\title{
The Influence and Mechanism of Corrosion on AZ31B Magnesium Alloy in 1,2-propanediol Engine Coolant
}

\author{
Zi-wen Wang ${ }^{l}$, Wei Bai ${ }^{1, *}$, Yan Yang ${ }^{2}$, You Wu ${ }^{1}$,Chang-Wei Su ${ }^{1}$, Jun-Ming Guo ${ }^{1}$ \\ ${ }^{1}$ Key Laboratory of Resource Clean Conversions in Ethnic Regions, Yunnan Minzu University, \\ Kunming, 650500, PR China \\ ${ }^{2}$ Natural rubber and coffee Quality Supervision and Testing Center of Yunnan Nong-Ken \\ *E-mail: bw369852147@qq.com
}

doi: $10.20964 / 2016.07 .80$

Received: 17 March 2016 / Accepted: 17 May 2016 / Published: 4 June 2016

\begin{abstract}
Corrosion mechanism of AZ31B magnesium alloys in 1,2-propanediol coolant has been studied using polarization curves, EIS, SEM and SEM- EDS. Magnesium alloy can be formed a stable and tight protective film in foundation liquid, which can easily be destroyed in the simulation solution. Little change in temperature on magnesium alloy reaction mechanism. But serious hydrogen evolution reaction occurs at high temperament on magnesium alloy surface in basis solution.
\end{abstract}

Keywords: Magnesium alloys; polarization curves; EIS; 1,2-propanediol coolant

\section{$\underline{\text { FULL TEXT }}$}

(C) 2016 The Authors. Published by ESG (www.electrochemsci.org). This article is an open access article distributed under the terms and conditions of the Creative Commons Attribution license (http://creativecommons.org/licenses/by/4.0/). 